One of the most remarkable cases is that of a young man who has been in the hospital occasionally since 1875 , and has been also out-patient, generally coming for advice after attacks of hæmoptysis, to which he is subject. He first came under my notice in March, 1877, and then gave a history of profuse hæmoptysis, but no inherited disease, nor history of previous cough. I examined him carefully, but could only detect want of expansion, and some dulness of percussion under the right clavicle; he had symptoms of hypertrophy of the heart, for which I could obtain then no reason, although I questioned him closely. He again came for advice in February of the present year, with an account of other attacks of severe hæmoptysis. This time I elicited the fact that he was a runner, and that the blood-spitting had occurred after racing, and after the exertion of lifting two hundredweight. When examined last he was losing flesh, and there was considerable flattening under both clavicles, chiefly under the left.

Other cases of this character have come under observation in which the blood-spitting has been the initial symptom, and has been the herald of a series of other symptoms, dyspnoea, emaciation, closely resembling the course of ordinary phthisis.

A tall, thin man presented himself in January last, with the following history. He had been in good health until two years and nine months before, when after running up a flight of stairs he threw up a great many mouthfuls of blood. Cough followed this after an interval of nine months. Again, five months before I saw him, when hurrying along to the Victoria Station, he spat up three quarts of blood. When I came to examine his chest, I found considerable flattening, chiefly of the left side, and the physical signs were those of scattered and localised crepitation, and an emphysematous condition between these patches, and in the neighbourhood.

There is another case under my care, a bricklayer, who while at work has been seized from time to time with severe hæmoptysis, and has been brought into the hospital spitting blood in large quantities. This case I have now watehed for two years. When he was first attacked with hæmorrhage, although I examined him very carefully I could only find the crepitant râle of blood under the right clavicle. For some time he continued at work, occasionally spitting blood, but within the last six months he has been losing flesh, suffers now from dyspncea and cough, and when I last saw him I found signs of softening at both apices, with considerable retraction and flattening of the chest. 1

The conditions which are to be noted in these cases and similar ones are exactly the converse of those observed in ordinary cases of phthisis. If authorities are consulted as to the initiatory signs and the signs of the progressive stages of phthisis, it will be found that there is a general agreement that the sounds indicate a progression from a substance to a fluid, with a corresponding aggravation of the constitutional symptoms ; in these cases, however, there is this remarkable difference, that the sounds indicate a gradual hardening of a fluid, the sounds being at first of a liquid character, and afterwards indicating a hard substance. In cases which are complicated by an advanced condition of phthisis, hæmoptysis results frequently in aggravation of the dyspnoea and subsequent emaciation from the occupation of the working alveoli by blood; this is sufficient to produce rapidly fatal results without time being given for the blood to harden and lose its colour. There is, however, a remarkable specimen, which I have recently put up in the hospital museum, showing the upper part of a lung excavated by a large cavity in which there are two aneurisms, the rest of the lung being occupied by white curdy material, which is in great measure altered blood.

If these observations are confirmed by others, the idea that blood produces phthisis by setting up a caseous pneumonia must be discarded, and from a review of the clinical signs which I have here given as those which are frequently found in cases of hæmoptysis, I think it is apparent that they camnot be interpreted with that notion in view, as they differ very materially from those that would result from a caseous pneumonia. If, however, the simple theory be adopted that blood is drawn back into the alveoli and there hardens and contracts, in a condition not very dissimilar to that of embolic clots in the lungs, the clinical signs are

1 Since this was written (last year) this patient has died; and at the examination, which I made myself, the condition of the lungs fully bore out the diagnosis made during his lifetime. readily interpreted, and the relation of blood-spitting to subsequent emaciation and pulmonary disease becomes very simple and intelligible.

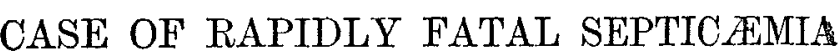 DUE TO A WHITLOW.}

By T. W. M'DOWALL, M.D.,

MEDICAL SUPERINTENDENT OF THE NORTHUMBERLAND COUYTY ASYLUM, MORPETH.

I AM tempted to place this case on record because it presents two features of special interest : first, the apparently trivial origin of the blood-poisoning; and, secondly, the severity of the symptoms and the rapidly fatal termination.

The patient, E. CMay, 1863, at which time she was fifty-five years of age. She was then in a state of mania, but continued so only for about a fortnight. She soon settled down, and became an industrious, quiet, and well-behaved woman, though she was sometimes transiently excited and abusive, using abominable language indicative of sexual delusions. During the fifteen years she lived in the asylum she enjoyed excellent health, and immediately before the beginning of her fatal illness was in remarkably good bodily condition for a woman age seventy years.

On the 13th, 14th, and 15th of December last she com. plained to the nurse of being " out of sorts," but she would not at first see a doctor, as she declared that she would soon be all right. She did not take her food with her usual appetite, was inclined to be sick, had slight headache, but she continued at her work, and was, to all appearance, only suffering from slight constitutional disturbance due to 2 small whitlow which had begun to form in the right thumb. During these three days she had tea \&c. in the way of food, and the thumb was diligently poulticed.

Dec. 16th. - Although she did not complain to the night nurse, she must have become much worse during the night, for she was so ill when she got out of bed, shortly after 6 o'clock, that my colleague was summoned to see her. She said that, in spite of having had plenty of bedclothes, she had been unable to sleep from a feeling of cold. She had also been purged twice. When seen by the assistant medical officer she was suffering from a severe rigor. She was ordered some brandy and hot water \&c., which made her, she said, feel more comfortable, but did not otherwise do any good. At 10 o'clock A.M. she was in a very prostrate state. The tongue was so abominably furred, and the month so clammy, that she could scarcely be understood when she spoke. The face was very pale and pinched; there was slight general tremor, but the skin was not cold. She lay on her right side with her face to the wall, quite conscious, but so ill that she did not care to be disturbed in any way. When asked if she suffered pain, she vaguely indicaterl her head or chest, but said nothing. The pulse was small, weak, and rapid. Thirst was urgent. As it was now quite evident that some very serious mischief was developing, she was placed in charge of a special nurse. No active treatment was adopted. Warm milk was given as often as she would take it, and the poulticing was continued. At 2 P.M. her condition was worse. She had been purged several times, the evacuations being thin, pale, and very offensive. The pulse was 150 , small, and irregular; respiration 40, and shallow; tempera. ture in the axilla $103^{\circ}$. Delirium now set in, and was almost constant, though she could easily be roused to consciousness by being addressed. Sometimes she struggled to get out of bed, saying that she must put on her clothes. When free from delirium she lay, as already described, on her right side, quite conscious and able to answer questions, but too ill to care to be disturbed. At 6, and again at 11 o'clock, it was noted that her general condition was gradually becoming more feeble, and that she had been purged several times during the afternoon, the evacuations continuing to be very fetid.

17th.-About 10 'clock in the morning her delirium became more violent; she was very restless, and constantly attempting to get out of bed. Collapse now set in, and she died in half an hour.

A post-mortem examination was made thirty-four hours after death. The following is an abstract of the notes:- 
External appearances: The body is fairly well nourished and free from all marks of injury. Hypostasis is well marked in dependent parts, and there are livid patches, about the size of a florin, on the skin of the thorax and abdomen. The skin of the tip and inside of the right thumb is livid, but not gangrenous. Post-mortem rigidity is well marked in both upper and lower limbs.-Head: The skullcap is densely adherent to the dura mater in the frontoparietal region. Beyond general atheroma of the arteries and some venous congestion of the pia mater, there is nothing calling for special remark. - Heart : The pericardium contains about an ounce of clear serum. Valves competent. All the cavities contain fibrinous clots partially decolourised. The clots are larger and firmer on the right side of the heart. -Lungs: Right adherent posteriorly by old fibrous bands; otherwise normal. Left contains two cicatrices at the apex, indicating the position of tubercular deposits, which have disappeared. - Spleen a little soft; otherwise normal. Liver normal. The gall-bladder contains many calculi, and a small quantity of almost colourless bile.-Kidneys : Right slightly congested throughout, and the capsule generally adherent. Left the same, and contains a few small cysts.Stomach contains about four ounces of slightly bilious fluid, mixed with particles of coagulated milk. The surface is free from all congestion; indeed it appears somewhat paler than usual.-Intestines contain nothing but milk in process of digestion. Though examined from end to end, no trace of congestion or alceration is found.

Remarks.-This case stands quite by itself in my experience, and I confess to having been in some difficulty in forming my diagnosis. During the last few days I have consulted articles on septicæmia in such works as I had access to, but without finding any similar record. That it is one of blood-poisoning there can be no doubt, I think. In describing the symptoms of septicamia, Bryant quotes from Simon as follows:- "If the wound become the seat of some large textural disorganisation, with consequent soakage of putrefying material, more marked signs of blood pollution may be expected to mix with or supersede those of common inflammatory fever; the patient's general state will then incline to be one of depression and apathy; his tongue will be more than commonly foul, and fetid diarrhœea will probably exist; or if perchance during the local process it happens (as is especially apt to be the case where cancellous bone-structure is affected) that pus passes up a vein into the general stream of blood, the patient's improvement is abruptly cut short by the severe recurrent rigors and sueating of pyomia, accompanied by local signs of secondary suppuration in parts to which the pus in conveyed." $1 \mathrm{He}$ also says :- "Confirmed blood-poisoning therefore is characterised not only by all the symptoms of inflammatory fever, but by severe rigors breaking in upon the febrile symptoms, by sudden and marked variations of temperature, by profuse sweats and great depression of the patient's powers ; and when these symptoms occur in the course of an attack of inflammatory fever, severe blood-poisoning is certainly indicated, the gravity of the attack being measured by the intensity of the symptoms." " "In feebler patients, who have no resisting power against disease, it is possible that even these pathological conditions [pneumonia in one or other of its stages] may not be found; life being as it were suddenly destroyed in the first onset of the bloodpoisoning." "The violence of the attack does not depend upon the severity or size of the wound ; for a trifling wound is at times followed by urgent symptoms; while a severe local injury may be followed by but few, if any, complications. Indeed, some of the severest cases of blood-poisoning are found in those in whom there is no wound."

As bearing on this case Dr. Bristowe's remarks are worth reproducing: "Pyæmia is generally an acute and quickly fatal disease; and when this is its character pyæmic deposits may almost invariably be found. The deposits, however, are not generally related numerically or otherwise to the severity of the case; and cases are sometimes observed which, judging from the symptoms during life and from other evidence, are truly cases of pyæmia, yet in which no pyæmic deposits are found." 4

Concerning those liable to attacks of pyæmia, Dr. Bristowe remarks; "It may be confidently asserted that the vast majority of pyæmic patients have not been suffering from chronic visceral diseases; that but few of those attacked are

1 Bryant's Practice of Surgery, p. $54 . \quad 2$ Ib., p. $54 . \quad 3$ Ib., p. 60. 4 Article "Pyæmia," Reynolds's System of Medicine, vol. i., p. 209. recovering from acute diseases; and that many, very many, victims of pyæmia have enjoyed the best of health up to the moment of the accident or the operation or the disease which has exposed them to the danger of pyæmia; and that even in many cases the wound (if wound there be) has been progressing favourably up to within a few days of the sudden onset of pyæmic symptoms." 5 As to its duration, he says : "The disease is generally very rapid in its course. Occasionally its duration is limited to three or four days; more commonly it lasts from six to eight days, and it may be for a fortnight." 6

I have quoted enough to show that the case now under consideration was a genuine case of pyæmia or bloodpoisoning. If some symptoms were wanting, this was due to the fact that the disease ran such a rapidly fatal course that there was no time for their development.

In conclusion, such a case might present great difficulties in a medico-legal way. Suppose it the subject of inquiry, no history to be obtained, and a medical man asked to ascertain the cause of death from a post-mortem examination-what could he certify?

\section{ON BLOOD-CLOTTING IN THE VESSELS.}

\section{By AUGUSTUS J. PEPPER, M.S., F.R.C.S.}

THERE is no more intricate problem awaiting solution at the hands of the clinical and pathological investigator than that of clotting of the blood in the vessels during life. Both as to the causes of the phenomenon and the subsequent changes, the most discrepant opinions have been entertained; each observer founding his own particular view upon some supposed facts met with in the history of this morbid statefacts not unfrequently mistaken in themselves, and inferences therefrom equally erroneous. Now we cannot be so very much surprised at this when we call to mind the many explanations that have been given by the most painstaking and competent authorities of the why and wherefore of coagulation of the blood removed from the body-e.g., the now discarded theories, firstly, of simple change of state of fibrin existing as such in the blood, and secondly, that of Dr. B. W. Richardson, who ascribed it to the escape of ammonia.

Before discussing the subject matter of my paper, I may perhaps be allowed to make a few remarks on the present state of our knowledge concerning the causes of coagulation of the blood drawn from the vessels. This is due to the interaction of three bodies-fibrinoplastin, tibrinogen, and a ferment, resulting in the combination of the two former; that is to say, fibrin which does not exist in the fluid blood comes to be formed under certain ascertainable conditions as the latter becomes solid. There is. an to speak, a constant antagonism between two sets of ir:fluences which tend in opposite directions-between those that favour and those that retard or prevent coagulation. Among the former are-1, rapid motion, as in whipping, or, in other words, multiplication of points of contact; 2, exposure to not-living matter. Among the latter we have1 , the addition of a third of the bulk of a saturated solution of some neutral salt; 2 , a temperature of about $32^{\circ} \mathrm{F}$.; 3 , moderate heat ; 4 , the abstraction of hæmoglobin ; 5 , the absence of a neutral salt, whose presence, according to Schmidt, is essential to coagulation.

Now blood, whilst in the vessels, is known to clot more easily when the current is slowed, just the reverse of what is found in shed blood; but this is only an apparent anomaly, for when we consider that slowing of the blood-current means a diminution in the nutrition of the coats of the vessel, and that this diminution of nutrition brings it to a state of lower vitality, the question of slowness or rapidity of flow is resolved into that of contact with foreign matter.

As to the so-called ferment-whether it be fiuid, or solid in the shape of germs visible or invisible-few can doubt the conditions under which what are termed the consequences of its action are brought about in the living body, and none can

5 Ibid., pp. 211, 212. 6 Ibid., p. 217. I Paper read before the Medical Society of St. Mary's Hospital, Feb. 5th, 1879 